\title{
Primer reporte de albinismo en vizcacha Lagidium viscacia (Rodentia: Chinchillidae) en los Andes de Perú
}

\author{
First report of albinism in vizcacha Lagidium viscacia (Rodentia: Chinchillidae) in Peruvian \\ Andes
}

\author{
Yulina Pelaez-Tapia*1 \\ https://orcid.org/0000-0002-4436-0708 \\ yulypelaezt@gmail.com \\ José R. Ayerbe ${ }^{1}$ \\ https://orcid.org/0000-0001-8312-4567 \\ biorolandoayerbe@gmail.com \\ Alejandro Portillo ${ }^{1,2}$ \\ https://orcid.org/0000-0003-2420-5791 \\ aportilloguizado@gmail.com \\ Luis Mamani ${ }^{2,3}$ \\ https://orcid.org/0000-0003-4233-4124 \\ luismamanic@gmail.com \\ *Corresponding author
}

1 Escuela Profesional de Biología, Facultad de Ciencias, Universidad Nacional de San Antonio Abad del Cusco (UNSAAC), Av. La Cultura 733, Cusco, Perú.

2 Museo de Historia Natural de la Universidad Nacional de San Antonio Abad del Cusco (MHNC), Paraninfo Universitario S/n (Plaza de Armas), Cusco, Perú.

3 Programa de Doctorado en Sistemática y Biodiversidad, Facultad de Ciencias Naturales y Oceanográficas, Universidad de Concepción, Concepción, Chile.

\section{Citación}

Pelaez-Tapia Y, Ayerbe JR, Portillo A, Mamani L. 2021. Primer reporte de albinismo en vizcacha Lagidium viscacia (Rodentia: Chinchillidae) en los Andes de Perú. Revista peruana de biología 28(3): e21136 (Agosto 2021). doi: http://dx.doi.org/10.15381/rpb v28i3.21136

$\begin{array}{ll}\text { Presentado: } & 06 / 04 / 2021 \\ \text { Aceptado: } & 30 / 06 / 2021 \\ \text { Publicado online: } & 30 / 08 / 2021\end{array}$

Editor: Leonardo Romero

\section{Resumen}

Se documenta el primer registro de albinismo de vizcacha (Lagidium viscacia) con base en dos individuos avistados en el departamento de Apurímac, en Perú. Este registro representa el primer reporte de albinismo en la familia Chinchillidae.

\section{Abstract}

We report the first record of albinism in vizcacha (Lagidium viscacia) based on two adult individuals sighted in department of Apurímac, in Peru. This record represents the first report of albinism in Chinchillidae.

Palabras clave:

Albinismo; Apurímac; Chinchillidae; Lagidium viscacia; mamíferos.

Keywords:

Albinism; Apurímac; Chinchillidae; Lagidium viscacia; mammals.

\section{Introducción}

El patrón del pelaje y las variaciones de color de los mamíferos son características fenotípicas muy resaltantes, pues juegan un rol importante en la mantención del fitness de las especies (Rubio-Gutiérrez \& Guevara-Chumacero 2017, Xu et al. 2013). Estas variaciones de coloración tienen funciones importantes como el camuflaje, la comunicación intraespecífica y la regulación de procesos fisiológicos, que son importantes en el comportamiento de las especies (Caro 2005).

El color de la piel y del pelaje se debe a la presencia o ausencia de melanina (Searle 1968), habiéndose reportado dos tipos de melanina: la eumelanina, que está asociada a una coloración marrón y negra, y la feomelanina, asociada a los colores rojo y amarillo (Ito \& Wakamatsu 2003, Hoekstra 2006). Las anomalías atípicas de la coloración se deben a la cantidad y tipo de melanina que hay en el organismo, pudiéndose observar una coloración más clara, completamente blanca o más oscura, respecto del color típico del pelaje de la especie (Łopucki \& Mróz 2010). La coloración blanca atípica o el aspecto blanquecino de un animal o en parte de este, se denomina albinismo, y este está causado por la no producción o producción parcial de melanina (Miller 2005); esta falta o déficit se debe a una mutación genética, relacionada con la enzima tirosinasa, que es la encargada de catalizar la producción de melanina (Imes et al. 2006). Son conocidos tres tipos 
de albinismo: (1) albinismo parcial (piebaldismo), que es la pérdida de pigmentos en algunas áreas de la piel o del cuerpo; (2) leucismo, que es la ausencia o deficiencia del pigmento en el pelaje, pero no en los ojos y la piel; y (3) albinismo (albino puro), que es la ausencia completa de pigmento en todo el cuerpo, y se caracteriza por la coloración blanca del pelaje, superficie cutánea rosa, uñas rosas y ojos rojos (Miller 2005, Acevedo et al. 2009, Abreu et al. 2013).

Los reportes de albinismo en roedores son escasos en la literatura, ya que han sido registrados muy raramente (Čanády 2015), debido a que el fenotipo albino es la condición autosómica recesiva de un locus genético que afecta el color (Hain \& Leatherwood 1982). A nivel mundial se han reportado 68 casos de albinismo (albinismo puro) en el orden Rodentia, y que representan menos del 2\% de las especies (Romero et al. 2018, Stumpp et al. 2018, Ramírez et al. 2019, Dalapicolla et al. 2020). Los escasos reportes de observaciones en la naturaleza pueden estar relacionados con algunos efectos negativos que son consecuencia indirecta del albinismo, como deficiencias en el camuflaje, comunicación intraespecífica y termorregulación, lo que evitaría que estos fenotipos sean abundantes.

Lagidium viscacia (vizcacha) es un roedor perteneciente a la familia Chinchillidae, que es endémica de América del Sur (Perú, Bolivia, Chile, Argentina). En el Perú está distribuido entre las ecorregiones de puna, yungas, serranía esteparia y desierto costero, teniendo como hábitat principal la ecorregión de puna (Pacheco et al. 2009), habitando entre los 2500 y $5100 \mathrm{~m}$ de altitud. Las vizcachas habitan preferentemente en lugares áridos, abruptos y con grandes pedregales (Rowlands 1974), donde la presencia de rocas proporcionan espacios seguros para descansar, solearse, refugiarse de pre- dadores y para hacer sus madrigueras (Pearson 1948, Walker et al. 2000). Es una especie herbívora, que se alimenta de vegetales de consistencia dura, ricas en celulosa y de digestión difícil, como algunas especies de los géneros Stipa, Festuca, Senecio, Calamagrostis, Parastrephia y Distichia (Mann-Fischer 1978). El color del pelaje puede ser de diferentes tonalidades variando desde el gris claro, gris pardusco, crema, ocre hasta pardo oscuro, y normalmente existe una línea dorsal oscura bien marcada. Además, la parte ventral de su cuerpo suele ser más clara y la parte inferior de la cola es muy oscura, casi negra (Mann-Fischer 1978).

En este estudio se reporta por primera vez dos individuos de Lagidium viscacia (Molina, 1782) albinos dentro de una población natural.

\section{Material y métodos}

Durante una expedición realizada entre el 5 y 6 de julio del año 2018, en el departamento de Apurímac, provincia de Grau, distrito de Chuquibambilla, comunidad de Huichihua, en la quebrada del sector de Turno (14²13'0.08"S, 7251'7.86"W a $4175 \mathrm{~m}$ ) (Fig. 1) y con base en la información proporcionada por pobladores de la comunidad de Huichihua (localización de vizcachas con coloración atípica), se logró ubicar una población de vizcachas donde fueron observados dos individuos con coloración atípica (blanco). Las observaciones fueron de manera directa, durante la mañana, entre las 08:15 a 10:15 horas. Se realizaron registros fotográficos y filmaciones con ayuda de cámaras digitales Panasonic Lumix DMC-FZ70 (60X) y Nikon Coolpix P600 (60 X) a una distancia aproximada de 35 metros $\mathrm{y}$, además, se utilizaron binoculares Bushnell ( $10 \times 50)$. No se realizaron colectas, pero si se recogieron comentarios de los pobladores del distrito sobre las vizcachas.

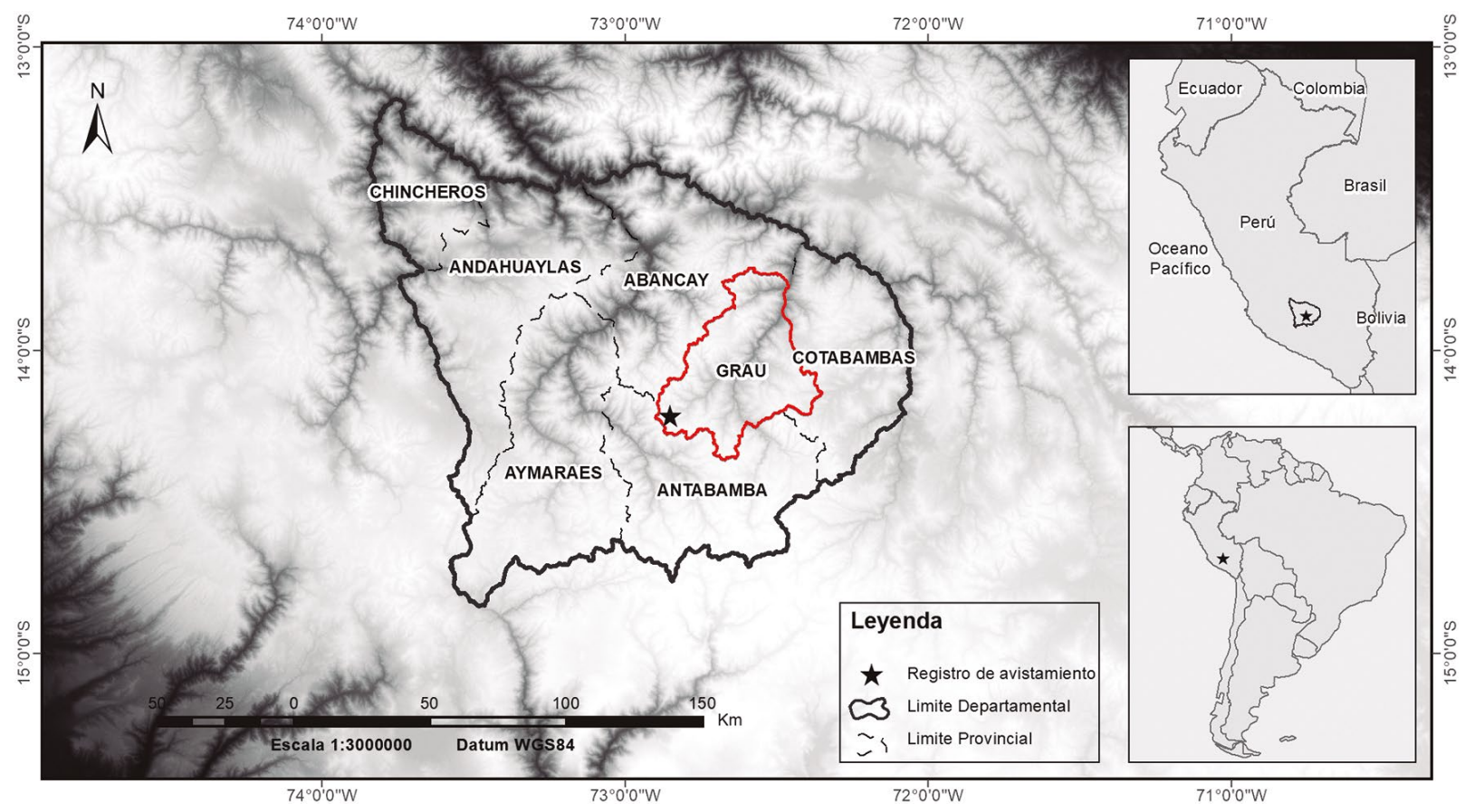

Figura 1. Mapa de ubicación, la estrella representa la ubicación de los individuos albinos de vizcacha. La línea roja representa el límite de la provincia de Grau. 
El lugar ocupado por esta población estaba dominado por rocas, con una cobertura vegetal mixta, entre especies herbáceas (Festuca sp., Calamagrostis sp., Distichia muscoides, entre otras), arbustivas (Senecio sp., Parastrephia sp., Gynopsis sp.), cactáceas (Austrocilindropuntia floccosa), pequeños parches de Qeuña (Polylepis sp.), y rodales de puya (Puya sp.).

\section{Resultados}

El 6 de julio de 2018 entre las 08:15 a 10:15 horas se registró mediante observaciones directas dos individuos albinos (albinismo puro) de vizcacha. Se encontraban separados una distancia aproximada de 10 metros. Los dos individuos se caracterizaban por el pelaje corporal de color blanco (cuerpo y cola), piel rosa (incluyendo la punta del hocico, orejas y patas), garras translúcidas e incoloras y cejas blancas. El iris del primer individuo fue rojizo (Fig. 2A, B) y no se logró observar el iris del segundo individuo porque durante toda la observación siempre los mantuvo cerrados (Fig. 2C, D).
En relación con su comportamiento, el primer individuo (Fig. 2A, B) fue observado alimentándose de "huaracco" (Austrocilindropuntia floccosa), entre otras hierbas y desplazándose de un lugar a otro y con breves periodos de descanso; mientras que el segundo (Fig. 2C, D) fue observado en el mismo lugar durante todo el periodo de observación y en compañía de otros individuos de coloración normal.

Dos pobladores locales informaron que individuos de coloracion blanca han venido siendo avistados desde hace muchos años. El señor Ruperto Valenzuela comentó haber visto individuos blancos desde que era un niño (desde hace 35 años aproximadamente), recordando haber observado uno o dos individuos por año. Sin embargo, recalcó que en algunos años no observó individuos con esta coloración. El profesor Laureano Pelaez comentó que en un lapso aproximado de 7 años (1983 - 1990) logró observar en tres oportunidades individuos de vizcacha de coloración blanca.
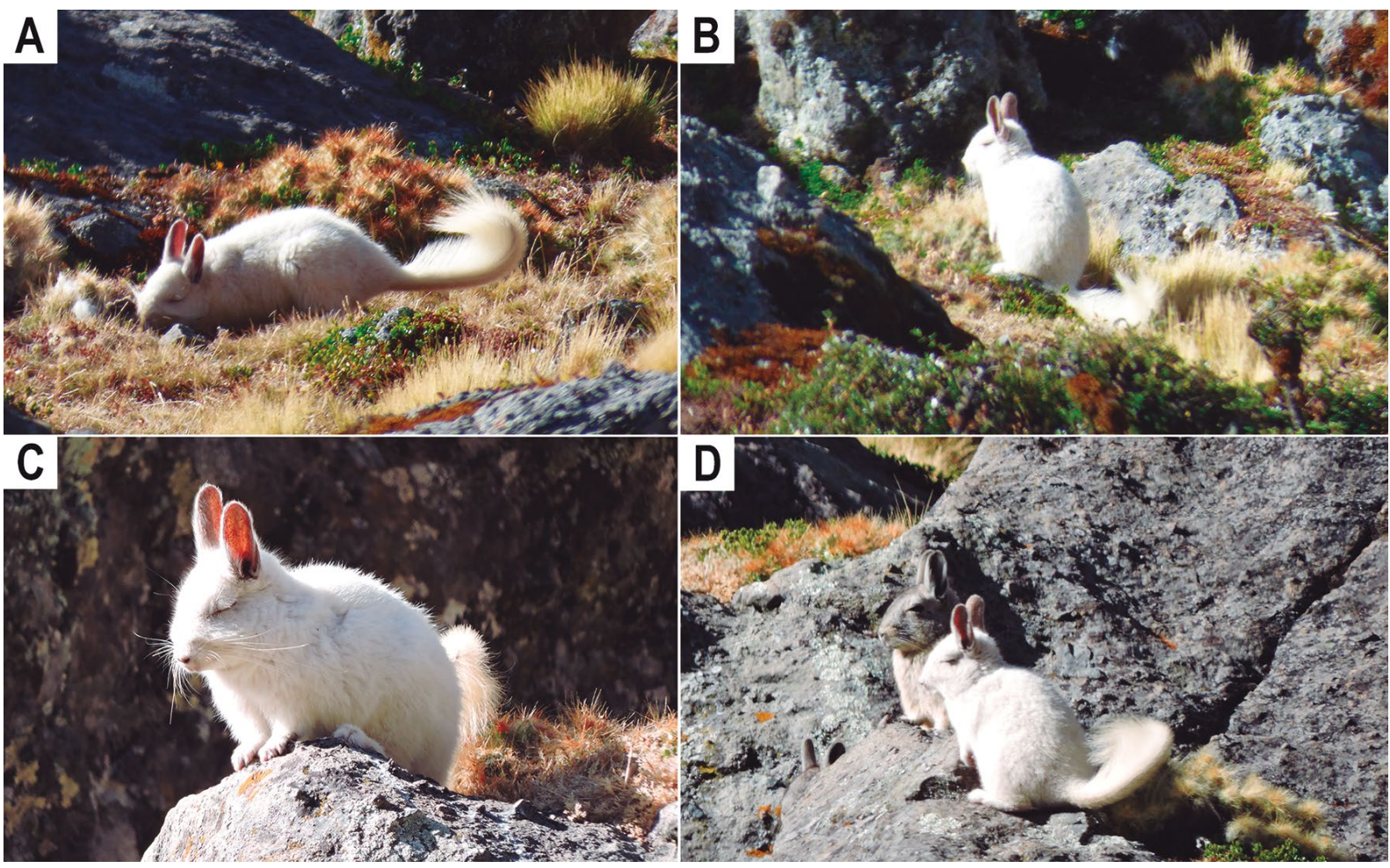

Figura 2. A, B registro del primer individuo albino; (A) individuo alimentándose de Huaracco (Austrocylindropuntia floccosa), (B) en su hábitat. C, D registro del segundo individuo; (C) tomando sol, (D) acompañado de otros individuos.

\section{Discusión}

De acuerdo con los reportes documentados y revisados de albinismo (albinismo puro) para roedores (Abreu et al. 2013), Romero et al. 2018, Dalapicolla et al. 2020), hasta el momento solo han sido reportados ocho casos en América del Sur (Tabla 1). Por lo que este reporte es el primer registro de albinos en la familia Chinchillidae y el primer registro de dos individuos con esta coloración en una población silvestre de vizcacha en el continente, representando el tercer reporte de albinismo en roedores en el Perú (Ramírez \& Arana 2005, Ramirez et al. 2019).
Las observaciones periódicas mencionadas por los pobladores locales en un lapso de muchos años (al menos 35 años), sumado a la presencia de dos individuos albinos en una misma población indicaría que la información genética para esta coloración atípica se mantiene en esta población de vizcachas. Además, podríamos esperar que esta población sea pequeña, aislada y con altos índices de endogamia (Bensch et al. 2000, Miller 2005, Chętnicki et al. 2007), ya que los alelos recesivos tienen mayores probabilidades de expresarse frecuentemente en poblaciones con estas condiciones. Otros factores que 
podrían intervenir en una alta frecuencia de albinismo en la población serian su hábito de vida en madrigueras subterráneas, los que servirían como refugio y dificultarían la depredación (Łopucki \& Mróz 2010); a lo que se sumaría, la baja presión de depredación por efecto de las actividades antrópicas sobre los depredadores de la vizcacha (Llanos et al. 2019, Silva-Rodríguez et al. 2009), o que por diversas razones las vizcachas no sean presas tan llamativos para sus depredadores (Miller 2005).

La principal función de la melanina en los ojos es evitar daños directos a la retina por la radiación solar y su ausencia hace que sean susceptibles a cegueras (Miller 2005), esto podría explicar el comportamiento del segundo individuo que, durante el tiempo de registro, siempre mantuvo los ojos cerrados. A pesar de que los individuos albinos podrían ser susceptibles a la depredación; la convivencia y el comportamiento social podrían ayudarlos a tener un crecimiento y desarrollo normal y puedan reproducirse y transmitir los genes de albinismo a las siguientes generaciones, permitiendo la presencia de estos fenotipos en la población durante el periodo como el mencionado por los pobladores locales.

Tabla 1. Reportes de albinismo puro en América del Sur.

\begin{tabular}{cllll}
\hline$N^{\circ}$ & Familia & Especies & País & Referencia \\
\hline 1 & Cricetida & Delomys dorsalis & Brasil & Cademartori \& Pacheco (1999) \\
2 & Cricetidae & Phyllotis andium & Perú & Ramirez \& Arana (2005) \\
3 & Cricetidae & Oxymycterus dasytrichus & Brasil & Stumpp et al. (2018) \\
4 & Octodontidae & Octodon degus & Chile & Díaz et al. (2015) \\
5 & Heteromyidae & Heteromys anomalus & Venezuela & Boher-Bentti et al. (2016) \\
6 & Erethizontidae & Coendou rufescens & Ecuador & Romero et al. (2018) \\
7 & Caviidae & Cavia tschudii & Perú & Ramirez et al. (2019) \\
8 & Echimyidae & Proechimys gardneri & Brasil & Dalapicolla et al. (2020) \\
\hline
\end{tabular}

\section{Literatura consultada}

Abreu M, Machado R, Barbieri F, et al. 2013. Anomalous colour in Neotropical mammals: a review with new records for Didelphis sp. (Didelphidae, Didelphimorphia) and Arctocephalus australis (Otariidae, Carnivora). Brazilian Journal of Biology. 73(1):185-194. https://doi. org/10.1590/S1519-69842013000100020

Acevedo J, Torres D, Aguayo-Lobo A. 2009. Rare piebald and partially leucistic Antarctic fur seals, Arctocephalus gazella, at Cape Shirreff, Livingston Island, Antarctica. Polar Biology. 32(1):41-45. https://doi.org/10.1007/ s00300-008-0500-6.

Bensch S, Hansson B, Hasselquist D, et al. 2000. Partial albinism in a semi-isolated population of great reed warblers. Hereditas. 133(2):167-170. https://doi. org/10.1111/j.1601-5223.2000.t01-1-00167.x.

Boher-Benti S, Cordero-Rodríguez GA, Caldera-Andara T, et al. 2016. Primer registro de albinismo en Heteromys anomalus y su distribución geográfica actualizada en Venezuela. Acta Biologica de Venezuelica. 36(1):19-32.

Čanády A. 2015. Records of partial albinism in house mouse (Mus musculus) from Slovakia. Zoology and Ecology. 25(3):199-202. https://doi.org/10.1080/21658005. 2015.1053306.

Cademartori, CV, Pacheco SM. 1999. Registro de albinismo em Delomys dorsalis (Hensel, 1872) (Cricetidae, Sigmodontinae). Biociências. 7(1):195-197.

Caro T. 2005. The Adaptive Significance of Coloration in Mammals. Bioscience. 55(2):125-136. https://doi. org/10.1641/0006-3568(2005)055[0125:TASOCI]2. $0 . \mathrm{CO} ; 2$.

Chẹtnicki W, Fedyk S, Bajkowska U. 2007. Cases of coat colour anomalies in the common shrew, Sorex araneus L. Folia Biologica. 55(1-2):73-76. https://doi. org/10.3409/173491607780006308
Dalapicolla J, De Oliveira Roth PR, Percequillo AR. 2020. First record of albinism in spiny rats of genus Proechimys (Rodentia: Echimyidae) from Western Amazon. Mammalia. 84(6):605-609. https://doi.org/10.1515/ mammalia-2019-0133

Díaz M, Barquez R, Verzi D. 2015. Genus Octodon Bennett, 1832. In: J. Patton, U. Pardiñas and G. D’Elía, eds. Mammals of South America, Volume 2: Rodents. University of Chicago Press, Chicago. Pp. 1029-1035.

Hain J, Leatherwood S. 1982. Two Sightings of White Pilot Whales, Globicephala Melaena, and Summarized Records of Anomalously White Cetaceans. Journal of Mammalogy. 63(2):338-343. https://doi.org/10.2307/1380654

Hoekstra H. 2006. Genetics, development and evolution of adaptive pigmentation in vertebrates. Heredity. 97(3):222234. https://doi.org/10.1038/sj.hdy.6800861

Imes DL, Geary LA, Grahn RA, et al. 2006. Albinism in the domestic cat (Felis catus) is associated with a tyrosinase (TYR) mutation. Animal Genetics. 37(2):175-178. https://doi:10.1111/j.1365-2052.2005.01409.x.

Ito S, Wakamatsu K. 2003. Quantitative Analysis of Eumelanin and Pheomelanin in Humans, Mice, and Other Animals: A Comparative Review. Pigment Cell Research. 16(5):523-531. https://doi.org/10.1034/j.16000749.2003.00072.x.

Llanos R, Andrade A, Travaini A. 2019. Puma and livestock in central Patagonia (Argentina): from ranchers' perceptions to predator management. Human Dimensions of Wildlife. 25(1):1-16. https://doi.org/10.1080/10871 209.2019.1668987.

Łopucki R, Mróz I. 2010. Cases of colouration anomalies in small mammals of Poland, and reasons for their incidence. Annales Universatis Mariae Curie-SkŁodowska. 65(1). https://doi.org/10.2478/v10067-011-0006-4. 
Mann-Fischer G. 1978. Los pequeños mamíferos de Chile: marsupiales, quirópteros, edentados y roedores. Gayana Zoología 40: 1-342

Miller JD. 2005. All About Albinism. Missouri Conservationist 66(6):4-7.

Pacheco V, Cadenillas R, Salas E, et al. 2009. Diversidad y endemismo de los mamíferos del Perú. Revista Peruana Biología 16(1):5-32. https://doi.org/10.15381/rpb. v16i1.111.

Pearson OP. 1948. Life History of Mountain Viscachas in Peru. Journal of Mammalogy. 29(4):345-374. https://doi. org/10.2307/1375125.

Ramirez DW, Quispe-López M, Marcelo-Carranza D, et al. 2019. Primer reporte de albinismo para el cuy silvestre Cavia tschudii (Mammalia: Rodentia). Revista Peruana de Biología. 26(4):521-524. https://doi.org/10.15381/ rpb.v26i4.17218.

Ramirez OE, Arana M. 2005. Albinism in the Andean leaf-eared mouse, Phyllotis andium (Rodentia, Cricetidae). Mastozoología Neotropical. 12(2):269-270.

Rowlands IW. 1974. Mountain viscacha. Symposium of the Zoological Society of London 34:131-141.
Romero V, Racines-Márquez CE, Brito J. 2018. A short review and worldwide list of wild albino rodents with the first report of albinism in Coendou rufescens (Rodentia: Erethizontidae). Mammalia. 82(5):509-515. https://doi.org/10.1515/mammalia-2017-0111.

Rubio-Gutiérrez IC, Guevara-Chumacero LM. 2017. Variación en la coloración y los patrones del pelaje en los felinos. Investigación y Ciencia. 25(71):94-101.

Searle AG. 1968. Comparative Genetics of Coat Colour in Mammals. Logos Press London. 308pp.

Silva-Rodríguez EA, Soto-Gamboa M, Ortega-Solís GR, et al. 2009. Foxes, people and hens: human dimensions of a conflict in a rural area of southern Chile. Revista Chilena de Historia Natural. 82(3):375-386. https://doi. org/10.4067/S0716-078X2009000300005

Stumpp R, Casali D, Cunha H, et al. 2018. Complete albinism in Oxymycterus dasytrichus (Schinz 1821) (Rodentia: Cricetidae). Mammalia. 83(3):281-286. https://doi. org/10.1515/mammalia-2018-0005

Walker RS. 2001. Effects of landscape structure on the distribution of mountain vizcacha (Lagidium viscacia) in the Patagonian steppe. Tesis, Doctor en Filosofía. University of Florida, Gainesville. https://ufdc.ufl.edu/ AA00028830/00001

Xu X, Dong GX, Hu XS, et al. 2013. The Genetic Basis of White Tigers. Current Biology. 23(11):1031-1035. https:// doi.org/10.1016/j.cub.2013.04.054

\section{Agradecimientos / Acknowledgments:}

Agradecemos a los pobladores de la comunidad de Huichihua, en especial a Ruperto Valenzuela por la información ofrecida y permitirnos realizar el trabajo de campo dentro de su jurisdicción. Al profesor Laureano Pelaez Sanchez por la corroboración de los avistamientos de los ejemplares albinos; a Yonathan A. Leandro por el diseño del mapa. YPT está muy agradecido con Cesar Medina (MUSA) y Marcelo Stucchi por la revisión del primer borrador de este manuscrito que, indudablemente, contribuyó a su mejora.

Conflicto de intereses / Competing interests:

Los autores declaran no tener conflictos de intereses.

\section{Rol de los autores / Authors Roles:}

YPT, JRA: realizaron el trabajo en terreno; YPT: preparo el primer borrador del manuscrito; YPT JRA, AP, LM: corrigieron, revisaron, editaron y aprobaron la versión final del manuscrito.

\section{Fuentes de financiamiento / Funding:}

Los autores declaran que el presente trabajo no contó con un financiamiento especifico.

Aspectos éticos / legales; Ethics / legals:

Los autores declaran no haber incurrido en aspectos antiéticos, ni omitir aspectos legales. 
Página en banco Blank page 